\title{
A meta-theoretical glimpse into the future of South African corporate communication management
}

\author{
Alet van Tonder and G. P. van Rheede van Oudtshoorn
}

\begin{abstract}
This article provides a concise discussion of meta-theoretical (critical-rhetorical, feminist and postmodernistic) approaches towards corporate communication management utilising meta-ethical points of departure with the aim of providing a glimpse into the meta-theoretical future of corporate communication management. The discussion is supplemented by an analysis of the challenges that face organisations in the fast-changing environment of the twenty-first century and corporate communication management as a critical/strategic management function that has the potential to assist organisations in adapting and remaining relevant to their environment, and by implication to the needs of their key internal and external stakeholders. The article is concluded by an explication of corporate communication management as being inextricably linked to ethical conduct and a product of the amalgamation of different meta-theoretical approaches, which interprets and advances the values of both stakeholders and the organisation in a manner that socially and ethically responsible, dialogical mutually adaptive, and contributes to democratising the organisation's decision-making and management processes. This poses challenges to, and insight into, the meta-theoretical approach held while engaging in discourse on the comprehensive nature of corporate communication management.
\end{abstract}

\section{Introduction}

Organisations operate within a challenging global environment. Within this global society, a modern, more progressive approach towards business is making an existential impact; an approach that embraces the so-called triple bottom line - the requirement of being profitable, combined with the requirements of being environmentally and socially responsible (King Committee on Corporate Governance 2002). Ethical behaviour, in this context, forms the basis of what is called socially responsible governance. South Africa is still undergoing fundamental socio-political, cultural and economic transformation. In the context of South Africa's history, there is an increased emphasis on corporate social responsibility, business ethics and ethical leadership that typifies a caring, people-centred approach (ubuntu) aimed at empowering people to develop as individuals and to take charge of their own destiny - with an emphasis on ensuring sustainable future development.

Inevitably, South African organisations no longer operate in isolation from the global environment. To become and to remain competitive, South African organisations are compelled to adopt internationally acknowledged best business practices and technologies, adapted to meet specific local needs and requirements or to develop 
proactively and innovatively approaches to business that can compare with the best in the world.

The internal and external stakeholders of South African organisations have a multicultural, multi-ethnic and multi-lingual character representing diverse personal backgrounds, experiences, values and ethical approaches. This dynamic environment dictates new, constantly changing approaches to cope effectively with the complexities that face organisations. A particularly daunting challenge for a business or organisation in South Africa is to find common ground in the sense of identifying shared values with which everyone in a diverse multicultural environment can identify. This requirement indicates an organisational/corporate culture conducive to creating the conditions in which people and the organisation can grow and prosper. The role of management in this is actively to communicate the strategic importance of business ethics and to ensure that it permeates every aspect of the organisational life by actively shaping an organisational climate that reflects a caring, ethical corporate culture. Dessler $(1985,462)$, as well as Verwey and du Plooy-Cilliers (2003, 113), indicates that a commitment to ethical behaviour should be entrenched in all the strategic processes, policies and the culture of the organisation and, importantly, it should be embraced by management as a way of (organisational) life.

Although individual employees are seen to be responsible for their own behaviour, it is the organisation's top leadership that is ultimately responsible for the culture of the organisation, including the ethical culture. This responsibility transcends into the future of the organisation: 'Good ethics is good business - if trust and good ethics are important today, they will be even more crucial in the future. No longer can leaders prosper at the expense of the common good while they hide behind the barriers of language, geography, or cover-up tactics. In this interconnected world, only ethical leaders and companies will survive' (Hackworth 1999, 3). Corporate communication management is regarded as a strategic management function, which is central to the sustained well-being of the organisation. It is responsible for proactively interpreting the organisation's environment, managing organisation-stakeholder relationships in a manner that is ethically and socially responsible and responsive, mutually adaptive and ensures a mutually beneficial, or at least acceptable, outcome.

Assuming the role of top corporate communicator implies a very powerful and responsible role in which the medium, the message and its interpretation by the recipient can be influenced by the communicator. The ethical and meta-theoretical orientation of the corporate communicator is therefore critical in ensuring that he or she always assesses the potential consequences of his or her communication for the recipient and respects the true dialogical nature of communication.

Amid the challenges facing South African organisations and the meta-theoretical progression of corporate communication management, an evolved paradigm for corporate communication management is becoming evident. Corporate communication seems 
ideally suited also to fulfil the role of the organisation's social conscience - a reflective role as moral ombudsman, ensuring that the organisation's relationships with stakeholders and society are morally and ethically responsible, accountable and responsive. Furthermore, corporate communication management is strategically ideally placed to stimulate change actively and to instil new approaches to management and organisational life. The underlying ethical and meta-theoretical unassailability of this evolving philosophy of corporate communication management warrants an in-depth investigation of the meta-theoretical framework that guides corporate communication, and will remain to guide corporate communication management into its future. Grunig (1992, 9-10) confirms this notion by pointing out that corporate communication as a management function serves both an idealistic social role, aimed at managing interdependencies and conflict between organisations and publics, and a critical social role, which assists in the construction, deconstruction and reconstruction of the organisational system by constantly criticising the organisation and the corporate communication function itself for poor ethics, and/or negative social consequences or ineffectiveness. In the South African context this idea is echoed by the King II report on corporate governance, which clearly indicates that profit alone will no longer ensure the well-being of the organisation. What is required is the maintenance of the delicate balance between the interests of shareholders (profit), the environment and people by nurturing the 'values, ethics and the reciprocal relationships with stakeholders' (King Committee on Corporate Governance 2002, 10).

\section{The meta-theoretical impact of ethics on corporate communication management}

In everyday language, ethics and morality are used as synonyms to describe what is good or right for human beings. Furthermore, it seems to involve those values that seek the well-being of other people. Ethical thinking and conduct happen when one takes into account personal interests, but simultaneously considers and protects the interests of others (Rossouw 1994, 2). Ethics can be said to be the 'study of morality, good, bad, right, wrong, human conduct and behaviour in a moral sense, and moral issues' (Thiroux 1998, 28). Considered as a working definition, morality or ethics 'deals basically with human relationships - how humans treat other beings so as to promote mutual welfare, growth, creativity, and meaning as they strive for good over bad and right over wrong' (Thiroux 1998, 31). Pfeiffer (2000, 2-3) maintains, 'Ethics may be viewed as the study of the justification of ethical value judgements. An ethical value judgment is a judgment of right

or wrong, good or bad, better or worse, virtue or vice, or what ought or ought not to be done. Justification involves giving reasons or evidence for the truth or falsehood of a given judgment.' Another issue raised by Pfeiffer is the principle of equal consideration of interest, which implies that one should make judgements and act in ways that treat the well-being and interests of others as no less than one's own (Pfeiffer 2000, 4). 
Verwey and du Plooy-Cilliers (2003, 102) define ethics as 'the set of principles, norms and values for morally acceptable behaviour held by an individual or group of people'. Ethical behaviour is seen as relating to the concepts and values of caring, truth, justice, responsibility and respect. The responsibility for organisational ethics is said to be an interrelated one between the community or society (the macro level), the organisation (the meso level) and the individual in the organisation (the micro level) (Verwey and du PlooyCilliers 2003, 102). In a work environment the corporate culture encompasses certain values and norms that assist in creating a more secure and comfortable work environment for employees (Vinten 1990, 10). Adams (1999, 27-28) states unequivocally that the essence of corporate communication is to be found in the conscience of the organisation. He sees the challenge for corporate communication in leading organisations in 'doing the right thing' and equates the concept of the organisational conscience with ethical corporate communication practised by corporate communication professionals who are ethical themselves, that is, adhere to ethical professional standards. This norm is to be achieved by ensuring that corporate communication/public relations is not used in a manipulative or propagandistic manner as in its early founding days. Instead, it should aspire to the normative ideal of engaging constituents in a dialogical communication process, by providing them with credible, dependable and timely information that they are entitled to have to enable them to make informed decisions or judgements. This coincides with the emphasis on good corporate governance, which implies that business should not only be responsible towards shareholders (intent on profit-making), but should also act in the best interest of the environment and society in general.

This teleological approach guides the corporate communication practitioner also to consider the social consequences of the organisation's behaviour, and to inform and advise management (as part of the strategic boundary spanning function of corporate communication) on the course of action that will be to the best advantage of both the organisation and its stakeholders. The importance of also acknowledging the voice of minority stakeholders as part of an ethical, dialogical, two-way communication process, however, points to a flaw in the utilitarian theory in the sense that it could be seen to sanction unethical behaviour if the results are good, or that the majority is necessarily always right and the minority wrong. To be truly ethical, decision-makers should consider the consequences of all their actions on all stakeholders - and this underlines the importance of the strategic function of corporate communication in the organisation.

Spicer (1997, 286-295) is quick to point out that stakeholders and organisations usually assess the moral implications of decisions/situations from different perspectives. Hence, they use different moral theories to analyse and resolve issues to judge the moral lightness of the process and the decisions that were made in the end. Management most commonly uses the utilitarian approach in decision-making (Spicer 1997, 287). Corporate communication specialists need to be aware of this and utilise the environmental scanning/research function to access information that can enhance (balance) decision 
making and ensure that the interests of both the organisation and the stakeholders are considered. Spicer (1997, 293-294), furthermore, points out that members of the organisation (called insider-actors) tend to limit the acceptance of responsibility and focus pragmatically on issues by trying to find a resolution according to the established ways of doing things. Stakeholders (outsider-observers), however, are more likely to assess the organisation's actions based on their perceptions of the organisation's degree of responsiveness and sensitivity to their needs. It is in the resolution of this problem that corporate communication management becomes crucial. Spicer $(1997,295)$ summarises this as follows: 'It is in the assessment of the moral issue, the acceptance of reasonable responsibility, and the ability to incorporate an observer's stance that distinguishes the public relations manager as communication ombudsperson in getting to the heart of the question, "What is the right thing to do?"'

\section{Critical-rhetorical approaches to corporate communication management}

Critical perspectives of corporate communication, like rhetorical perspectives, focus on the symbolic processes of the behaviour of organisations. Critical scholars of corporate communication, however, do not evaluate organisations and their messaging with a view to improving organisational management, advocacy or audience reach and understanding (like the rhetorical approach), but with the view of being confrontational - a role that could be described as that of playing the devil's advocate. Hence, the critical scholar would focus on finding answers to questions such as, 'Whose interests are served by organisational goals?' and 'What role do they play in creating and maintaining structures of power and domination?' (Toth and Heath 1992, 7).

Critical perspectives of corporate communication critically examine the domain of corporate communication with a view to 'enhancing] practices and further the evolution of the intellectual domain' (Dozier and Lauzen 2000, 4). In short, the critic's aims are to evaluate rhetorical effort or to account for effectiveness or ineffectiveness in rhetorical situations. One particular point of critique relating to stakeholder activism is that activism has been largely studied from the perspective of organisations that have sufficient financial power to appoint corporate communication practitioners and hence the research agenda is dominated by the organisational perspective - 'a research agenda that tends to favour the interests of the status quo, a legitimate ethical concern' (Dozier and Lauzen 2000, 7-8). Dozier and Lauzen (2000, 14-16) state that critical theory informs corporate communication theory in at least four ways, namely it

1. introduces new concepts that contribute to theory

2. shifts the attention from the organisational level of analysis towards both the societal and individual levels

3. highlights the moral and ethical contradictions in corporate communication 
4. helps to make sensible the unreasonable behaviour of activists that are linked to social movements.

Rhetoric comprises the words and visual symbols used by people in society to share and evaluate information, to shape beliefs and to establish norms for co-ordinated, collective action. From a narrow perspective, a rhetoric paradigm for corporate communication can be said to assume the 'assertion of self-interest', that is, the application of rhetoric to achieve compliance, goodwill, understanding, appreciation and action - the creation of images and the management of reputations (Toth and Heath 1992, 17-18). Rhetoric is usually intent on persuasion (one-way communication), yet it in essence concerns dialogue. In its most positive application, rhetoric is defined as 'dynamic exchange by which interested parties seek to induce agreement and action' (Toth and Heath 1992, 10). Unionisation and environmentalism are two responses by groups of individuals to counterbalance the power of large organisations. From the perspective of the organisation, the focus of corporate communication rhetoric is to create opinions that influence how people live, to establish identity for a product, service or the organisation in itself, and to improve relationships with people or stakeholders who are affected by the policies and actions of the organisation. Corporate communication, viewed from the rhetorical perspective, establishes a social discourse through slogans, axioms, metaphors, and so on, which shapes the way people/society perceive themselves, their environment and the organisation.

\section{The defining impact of feminist theories in corporate communication management}

Both rhetorical and critical scholars take a global approach that considers the organisation as speaker, with messages that influence social development and change. It has been suggested that 'the most effective public relations grows out of an entire world view that is feminine. That is, public relations that is practised as balanced, two-way communication between an organisation and its stakeholder groups stand to make the greatest contribution to organisational effectiveness ... women see themselves as the conscience of the organisation ... men ... consider themselves "dominant outsiders"' (Grunig, Toth and Hon 2000, 59). Holtzhausen (2000, 70) confirms that a number of scholars believe that corporate communication 'would be more ethical and effective if female models of cooperation and equity were used'.

The feminist approach is seen to value relationship building, symmetrical communication and co-operation, which are traits that have been found to enhance communication excellence. It is argued that if organisations continue to value only masculine values, such as efficiency, rationality, individualism and competition, then 'only their vested interests will be served' - an approach that is decidedly unethical. This is especially relevant in an era where stakeholders place a high premium on accountability and ethical behaviour of 
business. From a critical perspective, the study/research of relationships is a key question in corporate communication. Grunig, Toth and Hon $(2000,65)$ state that the embracing of feminine values should help define the field and clarify its purposes. The feminist approach, with its emphasis on values such as respect for diversity, nurture, empowerment, perceptiveness and honesty, holds the promise of, at least, orientating scholars and practitioners of corporate communication to the fact that incorporating these values in the way they conduct their business could increase their own efficiency, and the efficiency of the business or company.

In the postmodern era, characterised by technology and the requirement of profit-making, there seems to be a corresponding requirement to be socially and environmentally responsible and responsive. Indeed, this acknowledgement points to the incorporation of feminist values in communication management. 'The reinstatement of community, the development of relationships, and the resolution of conflict', described as the purpose of corporate communication, 'will be grounded in the character of those' who practise corporate communication (Grunig, Toth and Hon 2000, 65).

\section{Corporate communication management in a postmodern environment}

Postmodern theorists maintain that developments in contemporary media, communication and information technologies, together with the current processes of change and transformation experienced globally, are producing a new postmodern society that requires new concepts and theories. Postmodernism is characterised by an increasing plurality of beliefs, while consensus has become an outdated and suspect value. It is undesirable for researchers to pursue the obvious at the expense of the unusual (Kilduff and Mehra 1997, 461- 462). Cultural values of relativism, plurality and chance (Murphy 1996, 96) are central to postmodern thought. Chaos and complexity theories stand out as major exponents of a postmodern approach. Stroh $(1998,17)$ asserts that the increasing pace of change has created a new chaotic reality. Chaos theory creates a paradigm shift in postulating that 'forces of disorder, diversity, non-linearity, unpredictability and instability are controlling the universe'. Complexity theory refers to the study of 'many individual actors who interact locally in an effort to adapt to their immediate situation, thereby forming large-scale patterns that affect an entire society, often unpredictably and uncontrollably' (Murphy 2000, 447).

Postmodern theories can assist the corporate communication function to gain greater insight into the diverse nature of society and assist in finding solutions to some of the problems it faces. Holtzhausen $(2000,95)$ asserts that corporate communication is a product of both democracy and capitalism that has far-reaching effects on society and hence requires being 'understood and examined in a broader social, cultural, and political context rather than in a narrowly defined organisational function'. These approaches are 
seen to assist the corporate communication function in broadening its mind to enable the function/profession itself to adapt to its changing environment.

The postmodern view of power and politics offers an interesting and meaningful perspective on the application of postmodern theory to the field of corporate communication. It offers an opportunity for the corporate communication function, as well as the practitioner to play an activist role, hence enhancing the process of democracy and democratising decision-making processes of the organisation.

From the postmodern perspective, it becomes clear that an assessment of the signs and symbols of a culture helps to identify the allocation of power and the dominant coalition. Meaning in social context is created through the use of language, signs and symbols. Corporate communication can be seen to be involved in the production of symbols as cultural artefacts with political or economic reality for the individual in the organisational culture. This places a great responsibility on the corporate communication function to be inclusive rather than exclusive; to endeavour to anticipate and understand the world views of minorities and individuals. Corporate communication, in the effort actively to manage relationships and create mutual understanding, should acknowledge the diversity of meanings and understanding - that there can never be one single objective reality and that any choice of symbol, whether in language or images, 'implies an ideology, both a construction and a deconstruction of power, and a statement of difference' (Mickey 1997, 275).

Corporate communication theory is based on the positivist ideal of a single truth - which is deemed to be unattainable. In today's environment characterised by diversity and fragmentation, there can be no objective reality - reality, metaphorically speaking, is in the 'eye of the beholder'. By emphasising the existence of an increasingly diverse society, postmodernism empowers the corporate communication function to be more effective in managing diversity and plurality of ideas and influences.

Postmodernism sensitises the corporate communication practitioner to the principles that underlie the communication process - ideas, ethical codes and social obligation. For instance, an important postmodern consideration is that the mass media creates images that are not always supported by reality. This situation requires corporate communicators to act responsibly as communicators of integrity and substance (Kilduff and Mehra 1997, 463- 65). Furthermore, postmodernism asserts that in a democratic society everyone has the right to have his or her voice heard. However, because of the centrality of the sign/image, many minority views are not acknowledged because of their inability to create a sign or image to represent them. Hence, according to Mickey $(1997,80)$ corporate communication needs to 'be critical of signs that disenfranchise a segment of society'.

The role of the practitioner is opening up debate without forcing consensus - hence transforming the organisation into a more democratic institution - an idea supported by 
postmodern values. Postmodernism indicates that corporate communication should free itself from the so-called grand or meta-narratives by narrow-focusing on the details of a specific environment at a specific point in time. The role of corporate communication is to try and 'identify the tensors between the organisation and internal and external publics' and produce new meaning by harnessing divergent viewpoints (Holtzhausen 2000, 107). Applied to the field of corporate communication research, conducting research in the workplace will provide a communicative vehicle (channel) to employees and the organisation's publics. This implies that research will not be used to merely entrench those that hold power in the organisation. The creation of a critical, questioning, postmodern condition in corporate communication is set to enhance the effectiveness and applicability of the profession in the postmodern era.

The communication manager should accept responsibility for facilitating dialogue through what Spicer $(1997,278)$ calls the neutral 'outsider-observer' perspective. According to Spicer (1997, 296-297), communication practitioners have to understand both the internal and external perspectives and should assist each in understanding the other. Furthermore, the corporate communication practitioner who acts with integrity should not only acknowledge the values of the individual, but should also consider the consent of the broader society. This implies an impartial watchdog role - on behalf of society to ensure that the organisation acts ethically and responsibly in pursuing its business objectives. In short, the corporate communication practitioner should represent both the views of the organisation and its stakeholders (Spicer 1997, 293-294 in Leonard and Stroh 2000, 46).

A number of authors have identified 'respect for public interest, honesty, fairness, truth, integrity and accuracy as the basis for almost all codes of professional ethics for professional bodies' (Leonard and Stroh 2000, 47). It is proposed that these values should form the basis of ethical and socially acceptable organisational values, as well as the basis of the communication practitioner's mental make-up and professional attitude. Corporate communication as the strategic function concerned with the establishment and management of relationships has a major responsibility towards ethical decision-making.

\section{Perspectives on the meta-theoretical future of corporate communication management}

Corporate communication management does entail the more obvious role of management of all consciously used forms of expression of the organisation - whether it is in verbal, visual, non-verbal, symbolic or any other form. However, communication management also has a fundamental role to play as part of the organisation's strategic problem-solving processes. Corporate communication management is the strategic mechanism that proactively identifies and interprets the needs and expectations of both the organisation and its environment, and that strives to ensure that these needs and expectations are met, at least symbolically, or better aligned by providing a platform for the articulation of these 
needs and expectations. Hence, it can be said that corporate communication management facilitates dialogue between the organisation and its stakeholders in a manner that respects the fundamental rights of all parties to express themselves and their views through communication that conforms to the requirements of being honest, fair, ethical and responsible.

Corporate communication management can and should be conceptualised from a world view that values both the humanistic approach to management as the dominant paradigm in the postmodern era, as well as the feminist approach, which manifests in a communication management function that acts as the conscience of the organisation and which engages in communication that is practised according to the normative ideal of two-way symmetrical communication that enhances true dialogue. According to the dominant paradigm, organisations are regarded as individuals who can be held responsible and are seen as accountable for their intentions and actions, similar to individuals in a relationship or communication encounter. From a communication management perspective this implies that the same moral and ethical principles and requirements that guide communication and relationships between individuals also apply to organisations. Hence, communication management can be said to fulfil a role as the organisation's social conscience that manifests in the role of moral ombudsman for the communication manager (Adams 1999, 27-28).

From the insight gained by viewing corporate communication management from different theoretical perspectives, it can safely be postulated as a point of departure that, in the present and in the future, corporate communication management cannot truly fulfil its moral obligation towards the organisation and society if it does not embrace a strong ethical stance. The ethical requirements that are deemed essential for effective and efficient corporate communication management can best be described as a synthesis of the adherence to teleological ethics and, to a lesser extent, deontological ethics.

The teleological approach (also called utilitarianism or realism) defines ethical behaviour as that which is of the greatest good for the greatest number of people, while the deontological approach (also referred to as idealism or Kantianism) states that moral judgements should be grounded in an awareness of every individual's moral obligations and duty towards society, called the Theory of Rights by Spicer (1997, 286). In broad terms the value of these philosophical approaches to ethics for the corporate communication profession is that the critical assessment of the various theories 'should help shape intelligent reasoning on both a philosophical and practical level' (Leonard and Stroh 2000, 36).

This implies that one is guided in decision making by, (1) considering the consequences of one's actions and their potential impact on others and (2) by taking into account universal and rational principles of what is considered to be good or bad, right or wrong in any given situation. Corporate communication management should use the power of the 
function to lead management and organisations in general to act in a manner that is in essence altruistic.

It is ultimately the role of the corporate communication practitioner to interpret stakeholder (internal and external to the organisation) needs and responses, and to ensure that the organisation acknowledges stakeholder needs and makes decisions that are fair and equitable and balances the interests of the organisation, stakeholders and the environment. This requirement of good corporate governance conceptualises the corporate communication manager as an ethical ombudsman - a person with the ability to combine a rational, factual approach to business with a strong moral/ethical conviction that ensures a win-win outcome for everyone concerned. It follows logically that corporate communication management has a strong role to play in institutionalising ethical practices and to assist in the establishing of an organisational culture that embraces the organisation's core ethical and other values. Ideally, corporate communication management should be in such a powerful strategic position that it actively influences the process through which organisational values are created, in addition to ensuring that these values become a way of life for the organisation, its employees and its business partners/ stakeholders.

From a rhetorical-critical perspective, corporate communication management should actively contribute towards establishing a social discourse that can influence the way people and society perceive themselves, their environment and the organisation. This is an important role in corporate communication management, which has a responsibility towards the empowerment of people and society by portraying positive values with which more people can identify - an inclusive approach.

The postmodern era compels corporate communication management as the organisation's relational interface to assume an even more strategic role. Grunig, Toth and Hon (2000, 50) indicate that corporate communication as a management function contributes to organisational effectiveness by 'understanding and valuing the perceptions of diverse publics, inside and outside the organisation. The goal is collaborating with those strategic constituencies.' It is stated that progressive organisations value the corporate communication function for its demonstrated ability to manage strategically relationships with key stakeholders and to act as an ethical advocate or advisor to help organisations institutionalise ethical values that can contribute to business success (Seib and Fitzpatrick 1995, 21).

In the modern organisation, the communication manager's knowledge and experience of sophisticated (ethical) two-way symmetrical and asymmetrical communication techniques and their application as part of a well-balanced, mixed-motive model that aims at achieving a win-win situation for both the organisation and its stakeholders, is acknowledged as a key contributing factor to communication and organisational excellence (Dozier, Grunig and Grunig 1995). 
Furthermore, the communication manager with specialised knowledge of the application and interpretation of formal and informal research is acknowledged as the ears and eyes of the organisation - a person who, in the role of boundary spanner and strategist, assists management with gathering and interpreting information that guides the organisation's responses to the environment in an ethical and responsible manner (Leonard and Stroh 2000, 42). Corporate communication gathers intelligence about both hard business issues, and the softer issues that are important for organisational well-being, such as the values and expectations of internal and external stakeholders and the corporate culture. It is this professional approach that provides the communication manager with the power to participate in decision making and to advise the dominant coalition on ethical issues.

The creation of a critical, questioning, postmodern condition in corporate communication is set to enhance the effectiveness and applicability of the profession in the postmodern era. These challenges require the corporate communication function in itself to adapt fundamentally to its changing environment and to position itself proactively to perform those functions that will ensure the continued well-being of the organisation and its stakeholders. From this perspective corporate communication management, in acknowledging the dialogical, non-linear nature of the communication process, should actively promote an understanding of the possible diverse interpretations and understanding of those symbols and cultural artefacts that form part of the world view of the organisation's stakeholders. The challenge of practising ethical corporate communication management is indeed to transform the organisation into a more democratic/representative institution by opening up debate without forcing consensus, and to revisit existing discourse to identify its inherent biases (hegemony) and to redress that so that the communication process can become more inclusive. The postmodern approach to corporate communication management would imply the utilisation of a wide variety of communication tools and techniques so that smaller, individual communication communities can be reached more effectively.

Communication managers need actively to guide the organisation in the choice of communication channels, understanding different internal and external audiences and facilitating relationship-building in the quest for effective diversity management. In line with the postmodern way of thinking, the strength of the organisation is in acknowledging, nurturing and unleashing the cognitive potential of all employees - strength through diversity. Corporate communication management in the postmodern era needs to develop networks to facilitate a bottom-up approach to communication so that communication in itself can become a powerful positive force that stimulates innovation and creative solutions to organisational challenges. The corporate communication manager in the postmodern paradigm needs to assume visionary leadership and become a proactive agent for sustainable change without neglecting the values derived from feminist theories. Corporate communication management should act as a boundary spanner and buffer against uncertainty by providing strategic intelligence and guiding management on how best to respond to complexity and change. The more complex the 
environment becomes, the more the corporate communication manager should become involved in strategic management decision making. The communication management function, in helping to determine the organisational culture, forms an attractor that supports continuous change and adaptation. This is done by ensuring an adequate flow of information in the organisation, and by creating and translating symbols in the organisation that can facilitate shared meanings about its interpretation.

It is conceded that the future asks of corporate communication managers almost the impossible. Yet an amalgamation of the principles of contextualised ethical conduct, the utility value of critical-rhetorical points of departure, the inextricable links between feminist theories and corporate communication management, the richness of understanding gained from incorporating the divergent and innovative ideas of the marginalised, and insight into existential modes of surviving in a postmodern environment, can mean the difference between survival and defeat in the chaotic environment of the twentyfirst century.

\section{Conclusion}

Society and organisations in the twenty-first century are increasingly challenged to achieve shared meaning while focusing on effectively dealing with ever more diverse constituencies. Amid these challenges, organisations are increasingly pressured to become good corporate citizens. Holtzhausen $(2000,105)$ asserts that the practice of ethical corporate communication may be the biggest challenge for the profession in the twentyfirst century.

Corporate communication management, practised according to the normative ideal (symmetrical two-way communication), is acknowledged as a powerful strategic management function that sustains dialogue between the organisation and its environment and ensures that the organisation adapts to change and stays relevant and viable. Corporate communication management in the postmodern organisational setting has a golden opportunity, in fact, a window of opportunity to assert itself as a non-negotiable prerequisite for organisational and corporate success. This requires corporate communication management to assist the organisation in transcending diversity by

- assuming a moral role and acting as a moral ombudsman in challenging accepted/ dominant values in the organisation

- fostering reciprocal relationships with stakeholders other than stockholders, thereby demonstrating social concern

- promoting an inclusive approach to business and decision-making

- utilising persuasive power to influence the organisation's powerful dominant coalition to incorporate an ethical perspective in the organisation's decision-making processes. 
Plotting the meta-theoretical progression of communication management leads to the highlighting of corporate communication management to assist in democratising the organisational decision-making processes and to ensure that a wide variety of stakeholders become active participants in the organisational dialogue and discourse. In addition, communication as a means of self-expression and acknowledgement of the other as a party to the creation of meaning might be a theoretically archaic concept, but remains a pivot in the discourse on the meta-theoretical future of corporate communication management.

\section{References}

Adams, W. C. 1999. Resolutions for the new millennium. The Public Relations Strategist 5 (1):27-29.

Dessler, G. 1985. 4th ed. Management fundamentals: Modern principles and practices. Virginia: Prentice-Hall.

Dozier, D. M., L. A. Grunig and L. A. Grunig. 1995. Manager's guide to excellence in public relations and communication management. Mahwah, New Jersey: Lawrence Erlbaum Associates.

Dozier, D. M. and M. M. Lauzen. 2000. Liberating the intellectual domain from the practice: Public relations, activism, and the role of the scholar. Journal of Public Relations Research 12 (1):323.

Grunig, L. A. ed. 1992. Excellence in public relations and communication management. Hillside, New Jersey: Lawrence Erlbaum Associates.

Grunig, L. A., E. L. Toth and L. C. Hon. 2000. Feminist values in public relations. Journal of Public Relations Research 12 (1):49-68.

Hackworth, M. 1999. Only the ethical survive. Issues in Ethics 10 (2), Fall. http://www.scu.edu/ethics/ publications/iie/v10n2/ethical-surv.html (accessed 12 October 2003).

Holtzhausen, D. R. 2000. Postmodern values in public relations. Journal of Public Relations Research 12 (1):93-114.

Kilduff, M. and A. Mehra. 1997. Postmodemism and organisational research. Academy of Management Review 22 (2):453 481.

King Committee on Corporate Governance. 2002. King II Report: Executive Summary. http// www.iodosa.co.za (accessed 3 November 2003).

Leonard, A. and U.M. Ströh. 2000. Transcending diversity: The communication manager as ethical/ moral ombudsperson in the postmodern organisational setting. Communicare 19 (2):34-50.

Mickey, T. J. 1997. A postmodern view of public relations: Sign and reality. Public Relations Review 23 (3):271-281.

Murphy, P. 1996. Chaos theory as a model for managing issues and crises. Public Relations Review 22 (2):95-113.

-. 2000. Symmetry, contingency, complexity: Accommodating uncertainty in public relations theory. Public Relations Review 26 (4):447-462.

Pfeiffer, R. S. 2000. Ethics on the job: Cases and strategies. Belmont, California: Wadsworth.

Rossouw, D. 1994. Business ethics: A Southern African Perspective. Pretoria: Southern.

Seib, P. and K. Fitzpatrick. 1995. Public relations ethics. Harcourt Brace College: Orlando.

Ströh, U. M. 1998. Communication management in a millennium of chaos and change. Communicare $17(2): 16-41$. 
Spicer, C. 1997. Organizational public relations: A political perspective. Mahwah, New Jersey: Lawrence Erlbaum.

Thiroux, J. 1998. Ethics: Theory and practice. 6th ed. New Jersey: Prentice-Hall.

Toth, E. L. and R. L. Heath. 1992. Rhetorical and critical approaches to public relations. Mahwah, New Jersey: Lawrence Erlbaum.

Verwey, S. and F. du Plooy-Cilliers, F. 2003. Strategic Organisational Communication. Sandown: Heinemann.

Vinten, G. 1990. Business ethics: Busybody or corporate conscience? Leadership and Organization Development Journal 11 (3):4-11. 